The Open Nursing Journal
Bentham OPen
CrossMark
DOI: $10.2174 / 1874434601610010113$

RESEARCH ARTICLE

\title{
The Effect of Educational Intervention Regarding the Knowledge of Mothers on Prevention of Accidents in Childhood
}

Elayne Cristina Soares Silva, Maria Neyrian de Fátima Fernandes, Márcia Caroline Nascimento Sá, Layane Mota de Souza, Ariadne Siqueira de Araújo Gordon, Ana Cristina Pereira de Jesus Costa, Thábyta Silva de Araújo ${ }^{*}$, Queliane Gomes da Silva Carvalho, Carlos Colares Maia, Ana Larissa Gomes Machado, Fabiane do Amaral Gubert, Leonardo Alexandrino da Silva and Neiva Francenely Cunha Vieira

Federal University of Ceará, Alexandre Baraúna Street 1115, Rodolfo Teófilo, Fortaleza, Brazil

\begin{abstract}
Early guidance emphasizes the provision of information to families about growth and normal development in childhood such as specific information about security at home. This research aimed to analyze mothers' knowledge about the prevention of accidents in childhood before and after an educational intervention. It was conducted as a quasi-experimental study with 155 mothers in a Basic Health Unit in northeastern of Brazil in April and May of 2015. The data were collected in two stages through a self-report questionnaire performed before and after the educational intervention by the subjects. The results revealed a significant increase in knowledge about prevention of accidents in childhood in all the self-applied questions $(\mathrm{p}<0.05)$. After the educational intervention, there seemed to be a significant difference with the questions regarding the knowledge on preventing fall $(\mathrm{p}=0.000)$, drowning $(\mathrm{p}=0.000)$, and intoxication $(\mathrm{p}=0.007)$. The authors concluded that the educational intervention performed in this study increased the subjects' knowledge on prevention of accidents in childhood.
\end{abstract}

Keywords: Accidents, Child, Health Education, Intervention Studies, Knowledge, Nursing.

\section{INTRODUCTION}

Accident is defined as any casual event that results from a group of factors that make its occurrence more or less predictable by determining a recognizable injury; therefore, accidents can be prevented [1].

Accidents and violence constitute a set of health problems, in which are included accidental causes - due to traffic, work, home environment, and intentional causes - aggression, and self-harm that may or may not lead to death [2].

Current studies have implied that many accidents involving children happen at home environment since it is a place where they spend most of their time. Homes are conducive to accidents because they have several contributory elements, such as windows, stairs, sharp piercing objects and toxic products, etc [3, 4].

Accordingly, accidents at home environment are important threats to health and well-being of children worldwide. In addition, besides the life risk, accidents are responsible for intensive clinical complications, hospitalizations, physical and emotional consequences that may remain [1].

Parents or guardians' lack of information contributes to increase the incidence of childhood accidents. According to scientific studies, significant proportions of accidents occur from the lack of attention of adults and/or guardians and contempt of everyday risks, which are sufficient for the inattention of care, and they result in the occurrence of injury

\footnotetext{
* Address correspondence to this author at the Federal University of Ceará, Alexandre Baraúna Street 1115, Rodolfo Teófilo Zip Code 60430-160, Fortaleza, Ceará, Brazil; Tel: +55 (85) 98872-5365; E-mail: thabyta.araujo@hotmail.com
} 
[5]. Therefore, it is extremely important to monitor and pay attention on children since there are so many elements that increase the risk of injuries.

In the United States, childhood unintentional injuries are the leading cause of death among children ages 1 to 19 years, representing nearly 40 percent of all deaths in this age group. Each year, an estimated 8.7 million children and teens from birth to age 19 are treated in emergency departments (EDs) for unintentional injuries and more than 9,000 die as a result of their injuries - one every hour. While tragic, many of these injuries are predictable and preventable. Diverse segments of society are involved in addressing preventable injuries to children, like National Center for Injury Prevention and Control's (NCIPC) and Division of Unintentional Injury Prevention (DUIP) [6]

In an attempt to reduce the incidence of injuries resulting from accidents in childhood, many health policies and programs have been developed for this purpose around the world. The Brazilian Integral Child Health Program (PAISC), established in 1984, has the focus of attention on integral health promotion by monitoring child growth and development [7]. In addition, the Brazilian Federal Constitution of 1988 aims to ensure the child's right to life and health by the compliance of this legislation by family, society and state, since they must protect children from any negligence, discrimination, exploitation, violence, cruelty and oppression [8].

The Brazilian Ministry of Health has been seeking new ways to expand and strengthen the health care delivery, for example as through the Brazilian Family Health Strategy (ESF) at the level of primary care, which aims to improve health care and reduce morbidity/mortality in childhood [9].

However, although there are several health care services in force in Brazil such as the ESF that emphasizes the integral health attention to children, it turns out that there is still fragility and fragmentation of health care offered by health professionals. Consequently, it is noticed that even with the establishment of these health care services, many children under five years of age remain sick and require hospitalization from preventable causes, sequel, and progression to death $[4,7]$. This is due to the peculiar characteristics of childhood which make them more vulnerable to accidents, such as: physical and metal immaturity to predict and avoid the dangers, curiosity, ability to imitate and repeat some kind of behaviors, a poor motor coordination and head circumference is larger than the chest circumference that may predispose to more specific accidents $[4,9]$.

To direct specific actions to prevent accidents, it was established the Brazilian National Policy for Reduction of Mortality from Accidents and Violence, which is based on guidelines, such as: promoting the adoption of safe and healthy behaviors and environments, monitoring accidents and violence, systematization, amplification and consolidation of prehospital environment, interdisciplinary and intersectoral assistance to victims of accidents and violence, structuring and consolidation of services focused on recovery and rehabilitation, training of human resources and supporting the development of studies and research [7].

Based on the first guideline of the Brazilian National Policy for Reduction of Mortality from Accidents and Violence, health promotion is an important ally to prevent injuries through the guidance of the population on the prevention of accidents that occur at home. As a result, health professionals of primary health care services who daily take care of children who have suffered accidents at home have an important role regarding to share accurate information about prevention and stimulate caregivers to maintain the adoption of protection and prevention behaviours and environments [10].

Internationally, injury prevention includes strategies on many levels, such as preventing the injury event in the first place (e.g., removing hazards in the home), preventing or minimizing injury after an event has occurred (e.g., child safety seat in a crash), and reducing long-term consequences of injury (e.g., emergency medical services, rehabilitation). Another approach to injury prevention is a focus in the education because it can inform the public about potential risks and safety options and help people behave safely, like teaching expectant parents how to properly use a child safety seat when transporting their newborn [6].

The nursing approach to health care contributes to the fact that nurses establish a unique relationship with each patient, family and community and implement health education interventions by sharing their knowledge. These interventions should include dialogue, consider and value patients' experiences because it improves disease prevention and health promotion [11].

It is believed that nurses can cooperate through educational initiatives in health interventions in order to enhance the autonomy of parents/guardians in childcare related to prevention of domestic accidents [9]. That health interventions includes actions that simplify the access to information, which sensitizes parents about the risk and protective factors to 
intervene in the prevention and that inform them of the risks of domestic environments (e.g, safekeeping of toxic products) $[4,9]$.

Therefore, because of the extent of the problem in childhood accidents, the likelihood of prevention through guidelines, changes in the environment, and the lack of research on this topic in Brazil, this study aimed to analyze mothers' knowledge about the prevention of accidents in childhood before and after participating in an educational intervention.

\section{MATERIALS AND METHODOLOGY}

It is a quasi-experimental intervention study, before and after type [12], self-controlled, where each subject was used to control himself. In the current study, a control group was not necessary because the application instruments were made in a short period, so it cancels out any learning possibilities regarding the subject without an effective intervention.

The study was performed from April to May of 2015 in a Basic Unit of Family Health (UBS) in the city of Imperatriz, State of Maranhão, Brazil. The chosen UBS that is located in a peripheral area of Imperatriz city is the only available health care service to the population that surrounds this region. Because the geographical distance from downtown, the number of people who daily seek this UBS in order to get care and resolution of health issues has been increased significantly.

The sample was selected based on a non-probability sampling method. A convenience sample is a method which select a population sample that is accessible and available $[13,14]$. Thus, we selected 155 mothers who sought health care for their children at UBS during the investigation period.

The sample met the following inclusion criteria: mothers of children under five years of age, to agree taking part of the research by signing the consent term, and to participate in all stages of the research. Illiterate and/or mothers with medical diagnosis of cognitive/behavioral disorders were excluded from this research.

For data collection, a self-report questionnaire was used as an semi-structured instrument with multiple choice questions about sociodemographic variables (age, marital status, education, employment status, number of children), income (family income) and previous knowledge (what accidents are, how to prevent accidents, frequent accidents in childhood, preventing falls, preventing burn, preventing poisonings, preventing drownings).

Data collection involved the application of two questionnaires, one before and another one after the educational intervention.

The instrument used in this study for the pre-test and post-test was the "Mortality Reduction by Accidents and Violence", developed by the Brazilian Ministry of Health in 2003. This questionnaire includes questions on knowledge, opinions and attitudes related to the prevention of accidents and violence from childhood to old age. Before implementing the survey, all questions had language and understanding of issues validated in a pilot study. The questionnaires were self applied with the aid of a facilitator (average time of 30-45 minutes). It assessed knowledge about childhood accidents, along with the most common questions related to prevention of accidents, using questions, for example, on the most common types of accidents involving children, the prevention of burns in childhood, about the care with children nearly drowned and the age of the child with the highest prevalence of accidents.

The correct answers to the questions provided the knowledge about childhood accidents and were included in the statistical analysis.

The application of the pre-test questionnaire aimed to identify the knowledge about childhood accidents and analyze sociodemographic characteristics of the subjects. To conduct the pre-test, mothers were told about their participation and received a mechanical pencil and a wooden clipboard containing two consent terms (one to them and another one for the researchers) and the pre-test questionnaire.

Then, an expository and dialogued intervention that provided information on the subject of accident prevention in childhood lasting 30 minutes was performed. For the conduct of the educational intervention, it was used multimedia (projector and laptop).

The application of the post-test questionnaire was performed immediately after the end of the educational intervention in order to verify if there was an increase in the subjects' knowledge about the topic. The post-test questionnaire was given to the subjects at the end of the educational intervention. The authors emphasized that the 
questionnaire used in this step has the same questions of the pre-test questionnaire, except for the sociodemographic characteristics.

Regarding the data analysis, it was considered a quasi-experimental study to evaluate the knowledge of mothers on the prevention of accidents in childhood pre and post the education intervention. The data were analyzed through the mentioned variables of the questionnaire by using the chi-square test of Pearson at $5 \%$ significance.

It was also analyzed the mothers' knowledge question by question (before and after the educational intervention) by applying the linear trend chi-square test to compare pre and post interventions. In addition, it was calculated the frequencies of the characteristics through Fisher's exact test to verify if there was a significant increase in knowledge of mothers before and after the educational intervention. The data were tabulated in Excel 2013, and the tests performed by using SPSS, version 20.0 .

The research followed the ethical and legal aspects for its development as required by the Brazilian Resolution number 466/12 of the Brazilian National Health Council that is in charge of research involving human beings. It was assured for the subjects confidentiality and freedom for rejection or exclusion at any stage of the research [15]. The approval number of this research is $320 / 11$.

\section{RESULTS}

The current study included 155 mothers, the average age was 24.8 years (standard deviation=0.9 months), $43.6 \%$ of the interviewees had less than 9 years of education. The largest proportion of the subjects reported being married/common-law marriage (63.6\%). With regard to the employment status, the numbers showed an equal result ( $29.1 \%$ of the subjects claimed to be self-employed, and $29.1 \%$ homemaker). The data about the subjects' number of children and family income reveal that $65.5 \%$ had two to three children, and $50.9 \%$ had an income below the Brazilian minimum wage.

Table 1 shows the characterization of the occurrence of accidents in childhood. It was observed that the largest proportion of the subjects admitted an occurrence of accident episode with their children (63.6\%).

Table 1. Distribution of questions related to accidents in childhood, according to the interviewed mothers ( $n=155)$. Imperatriz, Brazil, 2015.

\begin{tabular}{|c|c|c|}
\hline Questions & $\begin{array}{l}\text { Total } \\
\text { n (\%) }\end{array}$ & P-value* \\
\hline $\begin{array}{l}\text { Accident occurrence with child } \\
\text { Yes } \\
\text { No }\end{array}$ & $\begin{array}{c}135(63.6) \\
20(36.4)\end{array}$ & 0.058 \\
\hline $\begin{array}{l}\text { Location of the accident }(\mathbf{n}=\mathbf{1 3 5}) \\
\text { At home } \\
\text { At school } \\
\text { In the street } \\
\text { Another location }\end{array}$ & $\begin{array}{l}124(43.6) \\
3(5.5) \\
4(7.3) \\
4(7.3)\end{array}$ & 0.000 \\
\hline $\begin{array}{l}\text { Age group of the child at the time of the accident } \\
0 \text { to } 1 \text { year } \\
1 \text { to } 3 \text { years } \\
3 \text { to } 5 \text { years }\end{array}$ & $\begin{array}{c}2(3.6) \\
124(43.6) \\
9(16.4)\end{array}$ & 0.000 \\
\hline
\end{tabular}

Source: Primary. Note: * Pearson chi-square test.

Among those who mentioned the occurrence of an accident, there was a statistically significant difference that points out home as the primary location of the accident ( $\mathrm{P}$-value $=0.000)$. The predominant age group in this event was one to three years $(43.6 \%)$.

Table 2 presents data related to the knowledge of mothers about childhood accidents before and after the educational intervention. A statistically significant difference before and after the educational intervention was found $(\mathrm{P}$-value $\leq 0.05)$. 
Table 2. Distribution of questions about the attention of interviewed mothers on accidents in childhood before and after the educational intervention ( $\mathrm{n}=155)$. Imperatriz, Brazil, 2015.

\begin{tabular}{|c|c|c|c|}
\hline \multirow[b]{2}{*}{ Questions } & \multicolumn{2}{|c|}{ Intervention } & \multirow[b]{2}{*}{ P-value } \\
\hline & $\begin{array}{c}\text { Before } \\
\text { n (\%) }\end{array}$ & $\begin{array}{l}\text { After } \\
\text { n (\%) }\end{array}$ & \\
\hline $\begin{array}{l}\text { What accidents are } \\
\text { Group of diseases that may or may not cause death } \\
\text { Group of random lesions that may or may not lead to death } \\
\text { Group of non-accidental injury that may or may not lead to death }\end{array}$ & $\begin{array}{c}8(14.5) \\
144(80.0) \\
3(5.5)\end{array}$ & $\begin{array}{c}5(9.1) \\
150(90.9) \\
0(0.0)\end{array}$ & $0.000^{a}$ \\
\hline $\begin{array}{l}\text { Accidents can be prevented } \\
\text { Yes } \\
\text { No }\end{array}$ & $\begin{array}{c}152(94.5) \\
3(5.5)\end{array}$ & $\begin{array}{c}154(98.2) \\
1(1.8)\end{array}$ & $0.322^{b}$ \\
\hline $\begin{array}{l}\text { Which of the following injury is more frequent with children } \\
\text { Drownings } \\
\text { Poisoning by medicines, cleaning products, plants, etc. } \\
\text { Falls } \\
\text { Burns }\end{array}$ & $\begin{aligned} 12 & (21.8) \\
5 & (9.1) \\
133 & (60.0) \\
5 & (9.1)\end{aligned}$ & $\begin{array}{c}0(0.0) \\
2(3.6) \\
146(83.6) \\
7(12.7)\end{array}$ & $0.000^{\mathrm{a}}$ \\
\hline
\end{tabular}

Source: Primary. Notes: ${ }^{\mathrm{a} C h i-s q u a r e}$ test for linear trend; ${ }^{\mathrm{b}}$ Fischer's exact test.

After the educational intervention, the major differences of knowledge of the subjects were related to the following items: accidents are a group of random lesions that may or may not cause death (from $80.0 \%$ to $90.9 \%$ ), falls are the most frequent accidents with children (from $60.0 \%$ to $83.6 \%$ ).

Table 3 indicates the subjects' knowledge about the prevention of accidents in childhood, before and after the development of the educational intervention. Regarding the prevention of burning, the subjects identified the following actions: to keep candles, hot food and lit cigarette out of children's reach (from $30.9 \%$ to $41.8 \%$ ), to check the temperature of bath water (from $16.3 \%$ to $21.8 \%$ ); to cover outlets with plastic shields (from $29.1 \%$ to $36.3 \%$ ).

Table 3. Distribution of questions about the attention of the interviewed mothers on the prevention of accidents in childhood before and after the educational intervention ( $n=155)$. Imperatriz, Brazil, 2015.

\begin{tabular}{|c|c|c|c|}
\hline \multirow{2}{*}{ Questions } & \multicolumn{2}{|c|}{ Intervention } & \multirow{2}{*}{ P-value ${ }^{a}$} \\
\hline & Before & After & \\
\hline $\begin{array}{l}\text { Ways to prevent burns (multiple answers are allowed) } \\
\text { Keeping pan handles outside the stove. } \\
\text { Placing candles, hot food and lit cigarette out of the reach of children. } \\
\text { Checking the temperature of bath water. } \\
\text { Covering outlets with plastic shields. }\end{array}$ & $\begin{array}{c}13(23.6) \\
117(30.9) \\
9(16.3) \\
16(29.1)\end{array}$ & \begin{tabular}{c|}
$0(0.0)$ \\
$123(41.8)$ \\
$12(21.8)$ \\
$20(36.3)$
\end{tabular} & \\
\hline $\begin{array}{l}\text { Poisonings are preventable by } \\
\text { Reusing the packaging of toxic products for other purposes. } \\
\text { Storing cleaning products, drugs and toxic products at the bottom of cupboards. } \\
\text { Storing cleaning products, drugs and toxic products in the upper of cupboards. }\end{array}$ & $\begin{array}{c}9(16.4) \\
18(32.7) \\
128(50.9) \\
\end{array}$ & $\begin{array}{c}2(3.6) \\
3(5.5) \\
150(91.0)\end{array}$ & 0.007 \\
\hline $\begin{array}{l}\text { To prevent drowning is required } \\
\text { To leave child playing at home under the supervision of another child when they are in the pool or elsewhere with } \\
\text { water since this enhance their development. } \\
\text { To be careful with children only when they are close to pools, river or sea because buckets and bathtubs with water } \\
\text { do not represent danger. } \\
\text { Children should always be under adult supervision and not play alone in places with water. }\end{array}$ & $\begin{array}{l}17(30.9) \\
126(47.3) \\
12(21.8)\end{array}$ & $\begin{array}{c}0(0.0) \\
4(7.3) \\
151(92.7)\end{array}$ & 0.000 \\
\hline $\begin{array}{l}\text { Fall prevention is performed by } \\
\text { Using walker when the child is learning to walk. } \\
\text { Using carpets on slippery roads. } \\
\text { Children should not be placed on tables, chairs and other furniture without adult supervision. } \\
\text { Allowing children to walk on wet and slippery roads. }\end{array}$ & $\begin{array}{c}22(40.0) \\
3(5.5) \\
128(50.9) \\
2(3.6)\end{array}$ & $\begin{array}{c}4(7.3) \\
0(0.0) \\
151(92.7) \\
0(0.0)\end{array}$ & 0.000 \\
\hline
\end{tabular}

Source: Primary. Note: ${ }^{\mathrm{a}}$ Chi-square test for linear trend.

In this study, before the educational intervention, $32.7 \%$ of the subjects reported not storing cleaning products, medicines and toxic products at the high level of cabinets (P-value $=0.007)$. However, after the intervention, $91.0 \%$ of the subjects claimed to perform these actions; therefore, it was obtained a statistically significant difference.

About the prevention of drowning, after the educational intervention, $92.7 \%$ of the subjects revealed to be necessary to have children under adult supervision in places with water $(\mathrm{P}$-value $=0.000)$. 
Regarding the preventing of falls, after the educational intervention, there was a statistically significant difference ( $\mathrm{P}$-value $=0.000)$ since $92.7 \%$ of the subjects affirmed that children should not be placed on tables, chairs and other furniture without adult supervision.

\section{DISCUSSION}

After the analysis of the collected data, it was noticed that the subjects did not have sufficient information to ensure the prevention of accidents in childhood before the educational intervention. By analyzing the mothers' knowledge before and after the educational intervention, there is an increase in percentage related to their knowledge compared to the step before the intervention. Therefore, it reaffirms the importance of regularly implementation of educational health interventions on this topic in communities.

The importance of accident prevention is required since accidents and violence are the third cause of mortality in the Brazilian population [9]. Because they are considered major public health problems, accidents in childhood can lead from temporary disability to death. Accidents have epidemiological causes and determinants that can be prevented and controlled and are usually the result of a set of factors that make their occurrence predictable [16].

According to the Brazilian National Policy for Reduction of Morbidity and Mortality of Accidents and Violence, accident is any unintentional and avoidable event, capable of causing physical and/or emotional injuries at home or in other social settings, such as traffic, work, school, sport and leisure [7].

Home environment is the primary location of accidents in childhood [17]. Therefore, the prevention of accidents at home must be shared to parents/guardians of the children by health professionals because this interaction in health care is considered a major factor on the risk prevention.

Studies have reaffirmed to be vital that families, especially mothers, are knowledgeable about the inherent risks of home environment in order to expand learning and risk identification regarding accident prevention in childhood, since ignorance predispose them to the occurrence of injuries $[18,19]$.

It is emphasized that the importance of providing subsidies to children's caregivers aims to reduce the incidence of injuries and deaths from this preventable causes through early guidance.

Traditionally, early guidance focuses on providing families information about normal growth and development in childhood, including specific information about security at home. Because of children's maturation skills, home safety measures need to be performed early in order to minimize risks [20].

For the emancipation and empowerment of subjects, health education is an essential tool for a suitable health care delivery because nurses, besides being caregivers, are educators [16]. Consequently, the teaching-learning process must be constant through actions and programs that collaborate to the acquisition of solid knowledge on principles and recommendations for the prevention of accidents in childhood.

The educational intervention performed in this study allowed the subjects to build a new perspective to the prevention of accidents at home in a way that they were motivated to apply the gained knowledge in childcare.

A study about the effectiveness of a multimedia intervention on the knowledge and actions of parents regarding children safety revealed significant increase of knowledge from the use of the educational intervention [21].

Parents' belief that accidents occur by chance is a major obstacle to their prevention and control, which confirms the importance of educational interventions. A study investigated the occurrence of accidents in a rural child population of Iran concluded that health professionals can play an important role in monitoring and identification of ways to prevent accidents related to the context in which children live [22].

Another research showed that nurses could provide to children's caregivers a consistent basis for risk prevention based on scientific evidence by sharing relevant knowledge [23].

Conducting studies that reinforces the concepts of scientific findings on the promotion of safety and accident prevention among children is fundamental to implement and strengthen educational programs on this field [24].

Among childhood accidents, falls, drowning, burns and poisoning are the leading causes of death in children aged from one to 14 years and are responsible for about 140,000 hospitalizations in Brazil per year [4].

Based on the epidemiological features of accidents among children, it was seen the urgent need for the development and implementation of interventions that stimulate and guarantee the child health promotion on the prevention of 
injuries, especially at home [11].

Studies have pointed out that the higher prevalence of these accidents in male children is falls (63\%). In fact, falls are primarily responsible for causing injuries/ trauma in children [5,9]. This scientific finding is consistent with the current research's results.

The high frequency of falls among children can be explained due to behavioral diversity of each sex and on cultural aspects. For example, boys are stimulated to play soccer and ride a bike. On the other hand, girls are more involved in quieter activities, such as playing with dolls, since it is culturally suitable [5].

It is also important to mention that age group is a contributing factor to the occurrence of accidents. To illustrate this assumption, the highest frequency of accidents occurs among children aged one to four years due to physical and mental immaturity and consequent lack of body sense/space. These characteristics are normal in this age group [16]. These data are consistent with the findings of the present study.

It is only after the Toddler stage that children present the development of self-balance and suitable spatial memory, and both of them indicate their autonomy without adult supervision. At this developmental stage, children begin to "discover" the world, wander and have a lot of curiosity even though their coordination has not been fully developed yet [20].

Nowadays in Brazil, 16.573 children were hospitalized due to injuries from burns and it represents $14 \%$ of all hospitalizations due to external causes in this population [5].

Accidental burns are more incidents in children under three years, particularly caused by hot substances, in which children pull containers with hot liquid and spill it on themselves. Therefore, it is essential that health professional workers tell parents about the importance of not allowing children in kitchen without adult supervision [23].

Younger children have lower perception of risk, greater vulnerability and dependence on adults related to safety and accident prevention by flammable liquids and materials [7]. Consequently, accidents at home are preventable through family orientation. It is also important to make physical changes in the environment, and preparation and implementation of some preventive behaviour [11].

Scientific field have claimed that accidents in childhood are related to neurodevelopment stage, highlighting the inexperience, inability to anticipate and avoid danger, curiosity, tendency to imitate adult behavior and lack of coordination. Other characteristics such as age, gender and personality (aggressiveness, impulsivity, hyperactivity and distraction), and some anatomical or organic characteristics, such as physical and/or mental disabilities are also mentioned [19, 24].

Regular supervision of parents or guardians in the Toddler stage is essential to pay attention to the risks of exposure to accidents [16]. The need for discovery of children is inherent to childhood; therefore, caregivers should adopt security mechanisms to protect them, such as outlet protectors, elimination of poisonous plants/poisons, protection on windows and pools, gates in ends of stairs, safety latches on toilets, safe place to store medicines, cleaning materials, etc [11]. Moreover, caregivers must be knowledgeable about the importance of prevention.

The current research has limitations, so the authors recommend the implementation of new studies that work on the effect of attitudes with different educational tools, the follow-up to the educational intervention and the sharing of information, more subjects and long-term evaluation in preventive care changes. Moreover, it is also suggested the participation of other subjects, such as parents, babysitters, grandparents, and all responsible for childcare, with interventions that involve the largest possible number of caregivers.

\section{CONCLUSION}

It was concluded that there was an increase of knowledge of mothers on the prevention of accidents in childhood through the educational intervention performed in this study.

Although educational tool used in the intervention was the media, it was realized its importance to facilitate discussion on the topic with the subjects. As a result, it is suggested to use it in later studies about other educational tools that enhance the teaching-learning process and shared discussion.

In terms of educational interventions on the prevention of accidents in childhood, the low number of researchers mostly provides information about epidemiological survey and literature reviews. In fact, there is a few number of articles about strategies for improving knowledge performed by nurses. 
The results of this study reaffirm the need to perform educational interventions to increase mothers' knowledge about prevention of childhood accidents because when these interventions are well planned and implemented, they benefit to subjects with the acquisition of knowledge that will influence their behaviors, own health and the health of their families.

\section{CONFLICT OF INTEREST}

The authors confirm that this article content has no conflict of interest.

\section{ACKNOWLEDGEMENTS}

Decleared None.

\section{REFERENCES}

[1] Matos KF, Martins CBG. Mortality by external causes in children, teenagers and young adults: a bibliographic review. Espaç saúde (Online) 2013; 14(1/2): 82-93.

[2] World Health Organization. Violence and injury prevention Geneva: WHO. Available from: www.who.int/violence_injury_prevention/en/. 2015 .

[3] Espitia-Hardeman V, Borse NN, Dellinger AM, et al. The burden of childhood injuries and evidence based strategies developed using the injury surveillance system in Pasto, Colombia. Inj Prev 2011; 17(Suppl. 1): i38-44. [http://dx.doi.org/10.1136/ip.2009.026112] [PMID: 21278096]

[4] Tavares EO, Buriola AA, Santos JA, Ballani TS, Oliveira ML. Factors associated with poisoning in children. Esc Anna Nery 2013; 17(1): 31-7. [http://dx.doi.org/10.1590/S1414-81452013000100005]

[5] Fernandes FM, Torquato IM, Dantas MS, Pontes Júnior FdeA, Ferreira JdeA, Collet N. Burn injuries in children and adolescents: clinical and epidemiological characterization. Rev Gaucha Enferm 2012; 33(4): 133-41. [http://dx.doi.org/10.1590/S1983-14472012000400017] [PMID: 23596927]

[6] Centers for Disease Control and Prevention, National Center for Injury Prevention and Control. National Action Plan for Child Injury Prevention. Available from: www.cdc.gov/safechild/pdf/national_action_plan_for_child_injury_prevention-a.pdf 2012.

[7] Brazilian Ministry of Health. Política Nacional de Redução da Morbimortalidade por Acidentes e Violências: Ordinance MS/GM number 737 of 05/16/01 2001., published on DOU no. 96 , section $1 \mathrm{E}$ of $18 / 5 / 01.1^{\text {st }}$ ed. $2^{\text {nd }}$ reprinted Brasília.

[8] Constitution of the Federative Republic of Brazil. Brasília: Brazilian Senate 1988

[9] Poll MA, Heck TW, Engel RH, Borges TAP, Rios AO, Carpes VAC. Falls of children and teens: preventing injuries through health education. Rev Enferm UFSM 2013; 3(Esp): 589-98.

[10] Pestana AL, Guline JEHMB, Senna MH, Nascimento ERP, Heidmann ITSB. Health promotion strategies and prevention of accidents in the home environment: a reflective analysis. Rev Enferm UFPE Online 2013; 7(11): 6524-32.

[11] Silva LD, Beck CL, Dissem CM, Tavares JP, Budó MD, Silva HS. The nurse and health education: a bibliographic study. Rev Enferm UFSM 2012; 2(2): 412-9.

[12] Fontelles MJ. Bioestatística aplicada à pesquisa experimental. $1^{\text {st }}$ ed. São Paulo: Livraria da Fisica 2012; Vol. 2.

[13] Miot HA. Sample size in clinical and experimental trials. J Vasc Bras 2011; 10(4): 275-8.

[14] Marotti J, Galhardo AP, Furuyama RJ, Pigozzo MN, Campos TN, Laganá DC. Sampling in clinical research: sample’s size. Rev Odontol UNICID 2008; 2(20): 186-94.

[15] Brazil. Health Ministry Brazilian Resolution no 466/2012. Available from: http://conselho.saude.gov.br/resolucoes/2012/Reso466.pdf 2013.

[16] Nascimento EN, Gimeniz-Pascoal SR, Sebastião LT, Ferreira NP. Inter-sector actions to prevent accidents in children education: teacher's assessments and students' knowledge. Rev Bras Crescimento Desenvolv Hum 2013; 23(1): 99-106.

[17] Amaral EM, Silva CL, Pereira ER, Guarnieri G, Brito GS, Oliveira LM. Incidence of accidents with children in a pediatric emergency room. Rev. Inst Ciênc Saúde 2009; 27(4): 313-7.

[18] Towner E, Mytton J. Prevention of unintentional injuries in children. Paediatr Child Health 2009; 19: 517-21. [http://dx.doi.org/10.1016/j.paed.2009.10.007]

[19] Cheraghi P, Poorolajal J, Hazavehi SM, Rezapur-Shahkolai F. Effect of educating mothers on injury prevention among children aged $<5$ years using the Health Belief Model: a randomized controlled trial. Public Health 2014; 128(9): 825-30. [http://dx.doi.org/10.1016/j.puhe.2014.06.017] [PMID: 25189328]

[20] Hockenberry MJ, Wilson D. Wong's Essentials of Pediatric Nursing. $9^{\text {th }}$ ed. St. Louis: Elsevier Mosby 2013.

[21] Snowdon AW, Hussein A, High L, et al. The effectiveness of a multimedia intervention on parents' knowledge and use of vehicle safety systems for children. J Pediatr Nurs 2008; 23(2): 126-39. 
[http://dx.doi.org/10.1016/j.pedn.2007.08.020] [PMID: 18339338]

[22] Rezapur-Shahkolai F, Naghavi M, Shokouhi M, Laflamme L. Unintentional injuries in the rural population of Twiserkan, Iran: a crosssectional study on their incidence, characteristics and preventability. BMC Public Health 2008; 8: 269.

[http://dx.doi.org/10.1186/1471-2458-8-269] [PMID: 18671856]

[23] Mahendra RR, Roehler DR, Degutis LC. NCIPC's contribution to global injury and violence prevention: past, present, and future. J Safety Res 2012; 43(4): 271-7.

[http://dx.doi.org/10.1016/j.jsr.2012.08.006] [PMID: 23127676]

[24] Malta DC, Mascarenhas MDM, Bernal RTI, Viegas APB, Sá NNB, Silva JB Jr. Accidents and violence in childhood: survey evidence of emergency care for external causes. Ciênc Saúde Coletiva 2012; 17(9): 2247-58.

(c) Silva et al ; Licensee Bentham Open.

This is an open access article licensed under the terms of the Creative Commons Attribution-Non-Commercial 4.0 International Public License (CC BY-NC 4.0) (https://creativecommons.org/licenses/by-nc/4.0/legalcode), which permits unrestricted, non-commercial use, distribution and reproduction in any medium, provided the work is properly cited. 